\title{
Original Article Study on $\alpha$-glucosidase enzyme inhibitory activity and DPPH free radical scavenging of green coffee bean extract (Coffea canephora)
}

\author{
Dang Kim Thu ${ }^{1}$, Vu Manh Hung ${ }^{2}$, Nguyen Thi Trang ${ }^{1}$, Bui Thanh Tung ${ }^{1, *}$ \\ ${ }^{1}$ VNU School of Medicine and Pharmacy, 144 Xuan Thuy, Cau Giay, Hanoi, Vietnam \\ ${ }^{2}$ Buon Ma Thuot University, 298, Ha Huy Tap, Tan An District, Buon Ma Thuot City, Dak Lak
}

Received 07 October 2019

Revised 10 October 2019; Accepted 16 October 2019

\begin{abstract}
: $\alpha$-glucosidase enzyme is one of the important molecular targets in the treatment of diabetes. In addition, free radicals are the cause of insulin resistance, damage $\beta$-cell pancreatic, glucose uptake disorders and induced diabetes. In this study we evaluated the inhibitory effect of $\alpha$ glucosidase enzyme and antioxidant effect by using DPPH free radical scavenging method of green coffee bean extract (Coffea canephora) and its fractions. Coffee beans were pulverized, extracted with ethanol $70 \%$ by sonications, and fractionated with n-hexane, ethyl acetate (EtOAc) and nbutanol (n-BuOH) solvents. Our results showed that coffee bean extract has a strong $\alpha$-glucosidase enzyme inhibitory activity, especially EtOAc fraction with an $\mathrm{IC}_{50}$ value of $2.21 \pm 0.04 \mu \mathrm{g} / \mathrm{mL}$. Furthermore, the coffee bean extract has an antioxidant effect by DPPH radical scavenging ability, and EtOAc fraction has the highest effect with an $\mathrm{IC}_{50}$ value of $25.69 \pm 3.08 \mu \mathrm{g} / \mathrm{ml}$. Our results show that green coffee beans and EtOAc fraction have potential effect in preventing and supporting for the treatment of diabetes.
\end{abstract}

Keywords: Coffee; Coffea canephora; free radical; $\alpha$-glucosidase; DPPH.

\footnotetext{
${ }^{*}$ Corresponding author.

Email address: tungasia82@gmail.com
}

https://doi.org/10.25073/2588-1132/vnumps.4180 


\title{
Nghiên cứu tác dụng ức chế enzym $\alpha$-glucosidase và quét gốc tự do DPPH của cao chiết hạt cà phê xanh (Coffea canephora)
}

\author{
Đặng Kim Thu', Vũ Mạnh Hùng² ${ }^{2}$ Nguyễn Thị Trang ${ }^{1}$, Bùi Thanh Tùng1,* \\ ${ }^{1}$ Khoa Y Duợc, Đại học Quốc gia Hà Nội, 144 Xuân Thủy, Cầu Giấy, Hà Nội, Việt Nam \\ ${ }^{2}$ Trường Đại học Buôn Ma Thuột, Số 298, Hà Huy Tập, Phuờng Tân An, TP. Buôn Ma Thuột, Đắk Lắk \\ Nhận ngày 07 tháng 10 năm 2019 \\ Chỉnh sửa ngày 10 tháng 10 năm 2019; Chấp nhận đăng ngày 16 tháng 10 năm 2019
}

\begin{abstract}
Tóm tắt: Enzym $\alpha$-glucosidase là một trong các đích phân tử quan trọng trong điều trị bệnh đái tháo đường. Ngoài ra, các gốc tự do là nguyên nhân gây ra sự kháng insulin, tổn thương tế bào $\beta$ tuyến tụy, rối loạn hấp thu glucose và bệnh đái tháo đường. Trong nghiên cứu này chúng tôi đánh giá tác dụng ức chế enzym $\alpha$-glucosidase và tác dụng chống oxi hóa thông qua khả năng quét gốc tự do DPPH của cao chiết hạt cà phê xanh (Coffea canephora) và các phân đoạn. Hạt cà phê được nghiền nhỏ, chiết siêu âm bằng ethanol $70 \%$ và tiến hành phân đoạn lần lượt với $n$-hexane, ethyl acetate (EtOAc) và n-butanol (n-BuOH). Kết quả cho thấy cao chiết hạt cà phê có tác dung ức chế enzym $\alpha$-glucosidase mạnh, đặc biệt là phân đoạn EtOAc với giá trị $\mathrm{IC}_{50}$ là $2,21 \pm 0,04 \mu \mathrm{g} / \mathrm{mL}$. Ngoài ra, cao chiết hạt cà phê có tác dụng chống oxy hóa thông qua khả năng quét gốc tự do DPPH và phân đoạn EtOAc có tác dụng cao nhất với giá trị $\mathrm{IC}_{50}$ là $25,69 \pm 3,08 \mu \mathrm{g} / \mathrm{ml}$. Kết quả nghiên cứu cho thấy hạt cà phê xanh và phân đoạn EtOAc có tiềm năng trong việc phòng ngừa và hỗ trợ điều trị bệnh đái tháo đường.
\end{abstract}

Tù khóa: Cà phê; Coffea canephora; gốc tự do; $\alpha$-glucosidase; DPPH;

\section{1. Đặt vấn đề}

Đái tháo đường là bệnh rối loạn chuyển hóa, có đặc điểm tăng glucose huyết do thiếu insulin hoặc do insulin bị kháng, hoặc cả hai. Tăng glucose mạn tính gây nên những rối loạn chuyển hóa carbohydrat, protid, lipid, gây tổn thương ở nhiều cơ quan khác nhau, đặc biệt ở tim và mạch máu, thận, mắt, thần kinh. Đến năm 2017, theo ước tính của Liên đoàn Đái tháo đường Quốc tế có khoảng 425 triệu người trong độ tuồi từ 20 đến 79 tuổi mắc bệnh trên toàn thế giới, và tiếp tục tăng lên dự kiến sẽ đạt 629 triệu người trưởng thành mắc căn bệnh này vào năm 2045 . Ở Việt Nam, cũng có khoảng 3,53 triệu người đang chung sống với đái tháo đường, chiếm $5,5 \%$ dân

\footnotetext{
* Tác giả liên hệ.

Địa chi email: tungasia82@gmail.com

https://doi.org/10.25073/2588-1132/vnumps.4180
} 
số cả nước [1]. Enzym $\alpha$-glucosidase là enzym tham gia trong bước cuối cùng của quá trình chuyển hóa carbohydrate. Ức chế enzym $\alpha$ glucosidase sẽ làm chậm sự hình thành glucose từ carbohydrate, làm giảm hấp thu glucose máu sau ăn. Acarbose, miglitol và voglibose là các chất ức chế $\alpha$-glucosidase đang được sử dụng hiện nay, nhưng chúng lại gây ra các tác dụng phụ trên đường tiêu hóa. Hơn nữa, oxy hóa stress có vai trò quan trọng trong việc phát triển các biến chứng trong bệnh đái tháo đường [2]. Do đó, ức chế enzym $\alpha$-glucosidase và chống oxy hóa stress là một trong các phương pháp để phòng ngừa và hỗ trợ điều trị bệnh đái tháo đường.

Chi cà phê, thuộc họ Rubiaceae, có 124 loài, trong đó các loài Coffea arabica, Coffea canephora and Coffea liberica là ba loài thường được sử dụng trong đồ uống [3]. Cà phê được trồng tại hơn 50 quốc gia trên thế giới, trong đó đứng đầu về sản lượng xuất khẩu là Brasil, Việt Nam, Indonesia và Colombia. Các hoạt chất chính trong cà phê là caffeine, axit chlorogen, lipid, sucrose, chất béo và protein, trong đó axit chlorogen và caffeine chịu trách nhiệm cho vị đắng của cà phê. Cà phê có tác dụng ngăn chặn quá trình tổn thương tế bào trong các bệnh tim mạch, ung thư và quá trình lão hóa, ngăn ngừa các bệnh huyết áp và tim mạch; tăng quá trình trao đổi chất; giảm nguy cơ đái thao đường type 2 [4]. Tai Việt Nam, hiện chưa có nghiên cứu nào về tác dụng ức chế enzyme $\alpha$-glucosidase và chống oxi hóa của cà phê liên quan đến khả năng hỗ trợ điều trị bệnh đái tháo đường. Vì vậy, chúng tôi tiến hành nghiên cứu này nhằm đánh giá tác dụng ức chế enzyme $\alpha$ glucosidase và tác dụng chống oxi hóa của cao chiết hạt cà phê xanh.

\section{Nguyên vật liệu và phương pháp nghiên cứu}

\subsection{Nguyên liệu}

Hạt cà phê $(1 \mathrm{~kg})$ được thu hoạch vào tháng 6 năm 2019 ở Buôn Ma Thuột. Mẫu nghiên cứu được giám định thực vật học bởi bộ môn dược liệu- dược cổ truyền, Khoa Y Dược, Đại học Quốc Gia Hà Nội. Hạt được làm sạch và sấy khô ở $50^{\circ} \mathrm{C}$. Hạt cà phê được nghiền nhỏ thành bột, tiến hành chiết xuất bằng ethanol $(\mathrm{EtOH}) 70 \%$, lặp lại 3 lần và gộp dịch chiết, lọc, và cất loại dung môi dưới áp suất giảm thu được cao chiết toàn phần ethanol $(512 \mathrm{~g})$. Cao chiết này được phân tán vào nước cất tỷ lệ $1: 1$ và chiết phân bố lần lượt bằng các dung môi có độ phân cực tăng dần $n$-hexan, ethyl acetate và $n$-butanol (mỗi dung môi 3 lần). Các phân đoạn được cất loại dung môi dưới áp suất giảm thu được phân đoạn tương ứng là $n$-hexane $(72 \mathrm{~g})$, ethyl acetate (218 g) và $n$-butanol (142 g).

\subsection{Phương pháp đánh giá tác dụng chống oxy hóa}

Hợp chất 1,1-diphenyl-2-picryhydrazyl (DPPH) có khả năng tạo ra gốc tự do bền trong dung dịch $\mathrm{MeOH}$ bão hòa, dung dịch có màu tím đỏ phản ứng với các chất chống oxy hóa để tạo ra phức hợp màu vàng không hấp thụ ánh sáng tử ngoại tại bước sóng $517 \mathrm{~nm}$ [5]. Khi cho chất vào dung dịch này nếu chất có khả năng quét các gốc tự do sẽ làm giảm cường độ hấp thụ ánh sáng của các gốc tự do DPPH. Mẫu thử được pha thành các nồng độ khác nhau. Hỗn hợp phản ứng gồm: $170 \mu \mathrm{l}$ dung dịch DPPH (nồng độ 0.24 $\mathrm{mg} / \mathrm{ml}$ ) trong methanol, $100 \mu 1$ dịch thử các mẫu và $730 \mu 1$ methanol được ủ ở $25^{\circ} \mathrm{C}$ trong 15 phút. Song song với mỗi mẫu thử, tiến hành đo mẫu chứng với cùng điều kiện và thành phần gồm: $830 \mu \mathrm{l}$ methanol và $170 \mu \mathrm{l}$ dung dịch DPPH (nồng độ $0,24 \mathrm{mg} / \mathrm{ml}$ trong methanol). Tất cả các thí nghiệm được lặp lại 3 lần. Hoạt tính quét gốc tự do DPPH được đánh giá thông qua giá trị phần trăm ức chế I (\%) và được tính theo công thức:

Trong đó:

$$
\mathrm{I} \%=\frac{\mathrm{Ac}-\mathrm{At}}{\mathrm{Ac}-\mathrm{Ao}} \times 100
$$

I \%: Hoạt tính chống oxy hóa

Ac: Độ hấp thu của mẫu chứng

At: Độ hấp thu của mẫu thử

Ao: Độ hấp thu của mẫu trắng (sử dụng methanol)

Tác dụng chống oxy hóa của dịch chiết được so sánh với chất chuẩn dương là acid ascorbic. Giá trị $\mathrm{IC}_{50}$ của mẫu được tính theo đồ thị nồng độ và \% ức chế (I\%). 


\subsection{Phương pháp đánh giá tác dụng ức chế enzyme $\alpha$-glucosidase}

Dựa trên phản ứng phân cắt cơ chất $\mathrm{p}$ Nitrophenyl- $\alpha$-D-glucopyranoside nhờ tác động của enzyme $\alpha$-glucosidase qua đó giả phóng sản phẩm là p-Nitrophenol có màu vàng.

p-Nitrophenyl-a-D-glucopyranoside $\stackrel{a-g \text { glucosidase }}{\longrightarrow}$ a-D-glucose + p-Nitrophenol

Độ hấp thụ của hỗn hợp phản ứng tại bước sóng $410 \mathrm{~nm}$ ở thời điểm 30 phút sau phản ứng, phản ánh lượng sản phẩm p-Nitrophenol sinh ra, sau đó phản ánh hoạt độ của enzyme $\alpha$ glucosidase [6].

Phương pháp xác định hoạt tính ức chế enzyme $\alpha$-glucosidase được thực hiện trên đĩa 96 giếng. Mẫu thử được pha loãng bằng DMSO và nước deion thành một dãy các nồng độ, nồng độ lần lượt phản ứng là $256,64,14,4,1 \mu \mathrm{g} / \mathrm{ml}$ hoặc pha loãng tiếp với mẫu hoạt tính nhỏ hơn $1 \mu \mathrm{g} / \mathrm{ml}$. Acarbose được sử dụng làm chất tham khảo.

Các thành phần phản ứng bao gồm $4 \mu \mathrm{l}$ phosphate buffer $100 \mathrm{mM} \mathrm{pH} \mathrm{6.8;25 \mu l \alpha -}$ glucosidase $0.2 \mathrm{U} / \mathrm{ml}, 10 \mu 1$ mẫu thử, $25 \mu 1 \mathrm{p}$ Nitrophenyl- $\alpha$-D-glucopyranoside $2.5 \mathrm{mM}$.

Ở mẫu đối chứng, mẫu thử được thay bằng đệm phản ứng. Thí nghiệm được ủ ở nhiệt độ 37 ${ }^{\circ} \mathrm{C}$. Sau 30 phút, phản ứng được dừng bằng 100 $\mu \mathrm{g} / \mathrm{ml} \mathrm{Na}_{2} \mathrm{CO}_{3}$. Độ hấp thụ được của phản ứng được xác định trên máy BIOTEK với bước sóng $410 \mathrm{~nm}(\mathrm{~A})$.

Khả năng ức chế enzyme $\alpha$-glucosidase của mẫu thử được xác định bằng công thức.

$$
\text { Độ ức chế \% }=\frac{\mathrm{A} \text { (đối chứng) }-\mathrm{A}(\mathrm{mẫu} \text { thử })}{\mathrm{A} \text { (đối chứng) }}
$$

$\mathrm{IC}_{50}$ là nồng độ ức chế $50 \%$ hoạt động enzym $\alpha$-glucosidase, được tính bằng phần mềm Tablecurve.

\subsection{Xử lý số liệu}

Các số liệu nghiên cứu được xử lý thống kê theo phần mềm SigmaPlot 12, Microsoft excel 2013. Số liệu được biểu diễn dưới dạng $\bar{X} \pm \mathrm{SD}(\bar{X}$ : giá trị trung bình của mẫu thử, $\mathrm{SD}$ : độ lệch chuẩn).
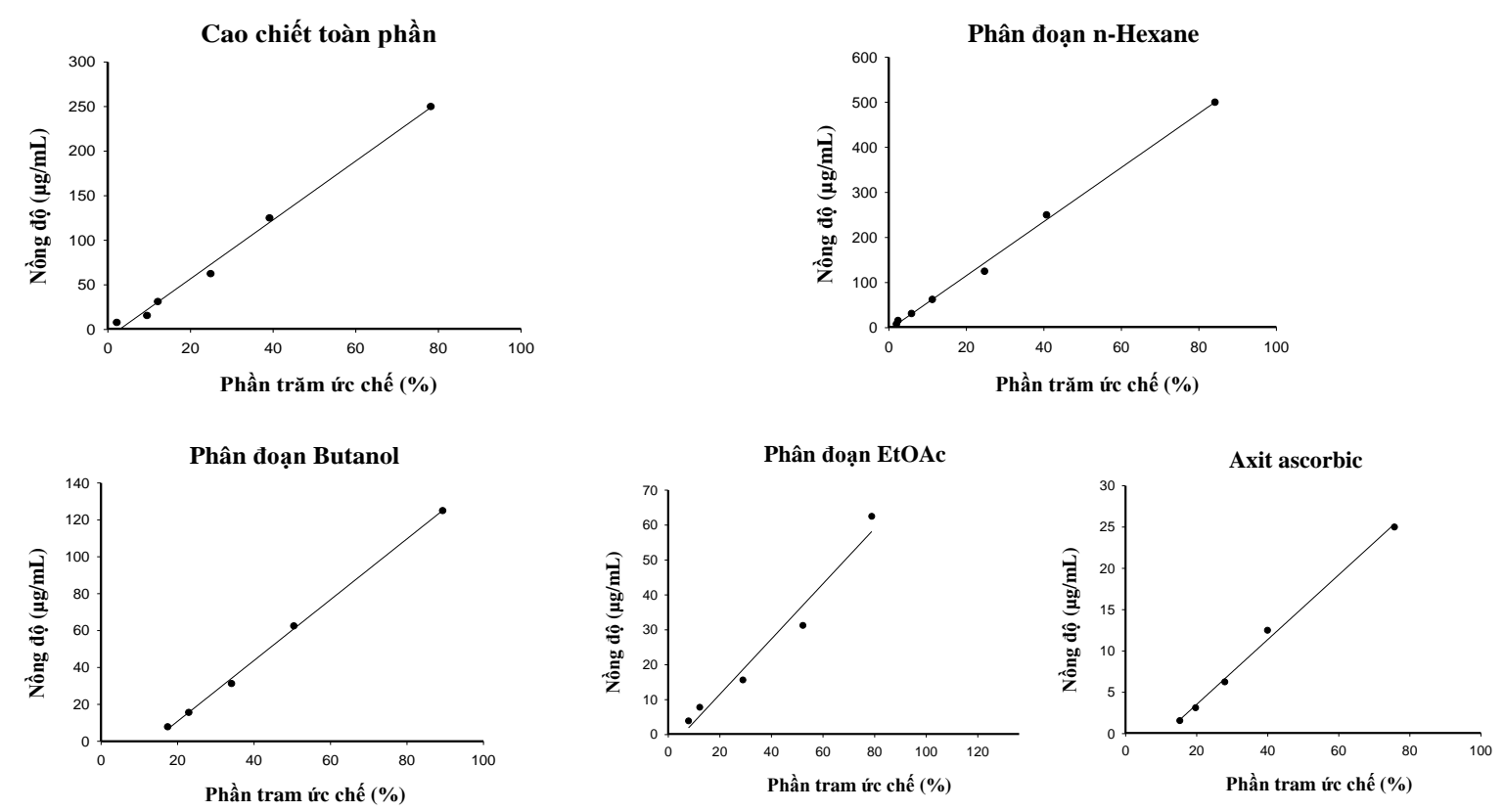

Hình 1. Đồ thị biểu diễn khả năng quét gốc tự do DPPH của cao chiết toàn phần, các phân đoạn hạt cà phê xanh và axit ascorbic. 
Bảng 1 . Giá trị $\mathrm{IC}_{50}$ của cao chiết toàn phần và các phân đoạn của hạt cà phê và acid ascorbic về khả năng quét gốc tự do DPPH

\begin{tabular}{llllll}
\hline Mẫu thử & Cao chiết toàn phần & n-Hexan & EtOAc & n-Butanol & Acid Ascorbic \\
\hline $\mathrm{IC}_{50}(\mu \mathrm{g} / \mathrm{ml})$ & $155,86 \pm 0,87$ & $295,21 \pm 0,93$ & $25,69 \pm 3,08$ & $61,09 \pm 1,02$ & $20,37 \pm 0,58$ \\
\hline
\end{tabular}

\section{Kết quả và bàn luận}

\subsection{Tác dụng chống oxi hóa}

Tác dụng chống oxy hóa in vitro trên mô hình quét gốc tự do DPPH của các mẫu thử cao chiết toàn phần và các phân đoạn n-Hexan, EtOAc và $n$-Butanol và mẫu chứng được trình bày ở hình 1 .

Từ kết quả ở bảng 1 cho thấy tác dụng quét gốc tự do DPPH in vitro của các phân đoạn phụ thuộc vào nồng độ. Trong các mẫu thử, phân đoạn EtOAc thể hiện tác dụng quét gốc tự do DPPH tốt nhất với $\mathrm{IC}_{50}$ là $25,69 \pm 3,08 \mu \mathrm{g} / \mathrm{ml}$, sau đó là phân đoạn Butanol và cao chiết toàn phần hạt cà phê với $\mathrm{IC}_{50}$ lần lượt là $61,09 \pm 1,02$ $\mu \mathrm{g} / \mathrm{ml}$ và $155,86 \pm 0,87 \mu \mathrm{g} / \mathrm{ml}$. Phân đoạn $\mathrm{n}$ Hexan thể hiện tác dụng chống oxy hóa yếu hơn với giá trị $\mathrm{IC}_{50}$ thu được là $295,21 \pm 0,93 \mu \mathrm{g} / \mathrm{ml}$. Song song với mẫu thử tiến hành tương tự với mẫu chứng là acid ascorbic thu được giá trị $\mathrm{IC}_{50}$ là $20,37 \pm 0,58 \mu \mathrm{g} / \mathrm{ml}$ cho thấy thí nghiệm hoạt động ổn định.

\subsection{Tác dụng ức chế enzym $\alpha$-glucosidase}

Kết quả thử hoạt tính ức chế enzym $\alpha$ glucosidase của các mẫu thử được trình bày ở bảng 2 .

Bảng 2. Kết quả $\mathrm{IC}_{50}$ của cao chiết toàn phần và các phân đoạn của hạt cà phê xanh

\begin{tabular}{ll}
\hline Tên mẫu & Giá trị $\mathrm{IC}_{50}(\mu \mathrm{g} / \mathrm{ml})$ \\
\hline Cao chiết toàn phần & $2,40 \pm 0,11$ \\
n-Hexan & $2,25 \pm 0,06$ \\
EtOAc & $2,21 \pm 0,04$ \\
n-Butanol & $5,90 \pm 0,56$ \\
Acarbose & $124,6 \pm 1,10$ \\
\hline
\end{tabular}

Qua bảng 2 cho thấy cao chiết toàn phần và các phân đoạn đều có tác dụng ức chế enzym $\alpha$ - glucosidase, đặc biệt là phân đoạn EtOAc có biểu hiện hoạt tính ức chế enzym $\alpha$-glucosidase mạnh với giá trị $\mathrm{IC}_{50}$ là $2,21 \pm 0,04 \mu \mathrm{g} / \mathrm{mL}$. Tiếp đến là cao hexan với giá trị $\mathrm{IC}_{50}$ là $2,25 \pm 0,06$ $\mu \mathrm{g} / \mathrm{mL}$ và phân đoạn $\mathrm{n}$-Butanol với giá trị IC50 là $5,90 \pm 0,56 \mu \mathrm{g} / \mathrm{mL}$.

Quá trình tăng glucose huyết của cơ thể sản sinh ra nhiều gốc tự do làm suy yếu hệ thống phòng thủ chống oxy hóa nội sinh [7]. Do đó để phòng ngừa và giảm các triệu chứng của bệnh đái tháo đường là sử dụng các chất chống oxy hóa là một biện pháp hữu hiệu [8]. Phương pháp quét gốc tự do DDPH được sử dụng rộng rãi để đánh giá khả năng chống oxy hóa. Kết quả nghiên cứu này cho thấy tác dụng của cao chiết toàn phần hạt cà phê xanh phụ thuộc vào nồng độ nghĩa là khi nồng độ chất tăng thì tác dụng quét các gốc tự do cũng tăng theo. Cao chiết toàn phần hạt cà phê xanh có khả năng quét gốc tự do DPPH đáng kể với $\mathrm{IC}_{50}$ là $155,86 \pm 0,87 \mu \mathrm{g} / \mathrm{ml}$; đặc biệt phân đoạn EtOAc thể hiện tác dụng quét gốc tự do $\mathrm{DPPH}$ cao với $\mathrm{IC}_{50}$ là $25,69 \pm 3,08$ $\mu \mathrm{g} / \mathrm{ml}$. Kết quả nghiên cứu về tác dụng chống oxy hóa của cà phê trong nghiên cứu này cũng tương đồng với các nghiên cứu trên thế giới. Babova $O$ và cộng sự đã nghiên cứu tác dụng quét gốc DDPH của cao chiết ethanol hạt cà phê xanh với 2 loài Coffea Arabica và Coffea Canephora cho thấy các cao chiết này có tác dụng chống oxi hóa cao, đặc biết là ở loài Coffea Arabica [9]. Alexandros Priftis và cộng sự đã chứng minh dịch chiết từ cà phê xanh và cà phê rang đều có tác dụng quét gốc tự do mạnh, ngăn ngừa được các tổn thương $\mathrm{ADN}$ do các gốc tự do gây ra [10]. Tương tự, Ningjian Liang và cộng sự chứng minh các hoạt chất có trong cà phê như caffeine, axit chlorogenic, melanoidins, trigonelline, cafestol và kahweol đều có tác dụng chống oxy hóa trên động vật và trên người [11]. Richtier Gonçalves cũng chứng minh dịch chiết cà phê có tác dụng chống oxy hóa thông qua tác 
dụng quét gốc tự do DPPH và $\operatorname{ABTS}(2,2$ 'azino-bis (3-ethylbenzothiazoline-6-sulphonic acid) [12].

$\alpha$-Glucosidase là một enzym nằm trong màng tế bào đường ruột, tham gia vào bước cuối cùng của quá trình tiêu hóa. Vì vậy, các chất ức chế enzym này sẽ làm giảm quá trình hấp thu đường từ đường tiêu hóa vào máu. Các chất ức chế enzym $\alpha$-glucosidase đã được sử dụng làm thuốc điều trị bệnh đái tháo đường typ 2 như acarbose, miglitol, voglibose [6]. Acarbose là thuốc tân dược dược sử dụng rộng rãi hiện nay và cũng là một chất chứng dương trong các nghiên cứu về tác dụng ức chế enzym $\alpha-$ glucosidase. Trong nghiên cứu này acarbose được sử dụng làm chất chứng dương cho các thí nghiệm đánh giá khả năng ức chế enzyme $\alpha$ glucosidase. Kết quả của nghiên cứu này cho thấy cao chiết toàn phần và các phân đoạn hạt cà phê xanh có tác dụng ức chế enzym $\alpha$ glucosidase mạnh so với acarbose. Như vậy, trong cao chiết hạt cà phê xanh có chứa nhiều hợp chất có tác dụng ức chế enzym $\alpha$ glucosidase. Vì vậy, hướng nghiên cứu tiếp theo sẽ tiến hành tách chiết các hợp chất từ cao chiết hạt cà phê xanh để phân lập các hợp chất có khả năng ức chế enzym này với giá trị $\mathrm{IC}_{50} \mathrm{cao}$. Kết quả nghiên cứu của chúng tôi cũng tương đồng với các công bố trước đây. Shin-Duk Kim đã phân lập hợp chất $\beta$-carboline alkaloid norharman (9H-pyrido[3.4- b]indole) từ hạt cà phê và cho thấy đây là hợp chất ức chế mạnh enzym $\alpha$-Glucosidase với $\mathrm{IC}_{50}$ là $180 \pm 3.2 \mu \mathrm{M}$ [13]. Ngoài ra, Zheng Yinan và cộng sự cho thấy dịch chiết nước của hạt cà phê ức chế enzym $\alpha$ glucosidase có thể là do hợp chất chính chlorogenic acid đảm nhiệm [14]. Trong nghiên cứu này, chúng tôi cũng chỉ ra rằng cao chiết hạt cà phê có khả năng ức chế enzyme $\alpha$ glucosidase, là bước ngăn cản quá trình hấp thu glucose, giúp hỗ trợ điều hòa đường huyết.

\section{Kết luận}

Nghiên cứu đã đánh giá được tác dụng chống oxi hóa và ức chế enzym $\alpha$-glucosidase của cao chiết hạt cà phê và các phân đoạn của cao chiết hạt cà phê xanh. Kết quả cho thấy cao chiết cà phê có tác dụng chống oxi hóa và ức chế enzym $\alpha$-glucosidase, đặc biệt là phân đoạn EtOAc. Kết quả này gợi ý cho việc nghiên cứu sâu hơn về thành phần hóa học của phân đoạn dịch chiết EtOAc để phân tách được các hợp chất tinh khiết có tiềm năng trong phòng, điều trị bệnh đái tháo đường.

\section{Tài liệu tham khảo}

[1] Federation ID. IDF Diabetes Atlas 8th Edition (2017).

[2] Wright Jr E, Scism-Bacon J, Glass L. Oxidative stress in type 2 diabetes: the role of fasting and postprandial glycaemia. International journal of clinical practice 60(3) (2006) 308.

[3] X. Chen. A review on coffee leaves: Phytochemicals, bioactivities and applications. Critical reviews in food science and nutrition 59(6) (2019) 1008.

[4] Chu Y-F. Coffee: emerging health effects and disease prevention. John Wiley \& Sons (2012).

[5] N.T. Hai, D.K. Thu, B.T. Tung. Sarcandra glabra Extract Protects against Scopolamine Induced Cognitive Deficits by Modulating Neuroinflammation and the Cholinergic System. Current Enzyme Inhibition 14(3) (2018) 210.

[6] B.T. Tung, D.K. Thu, P.T. Hai, N.T. Hai. Evaluation of $\alpha$-glucosidase inhibitory activity of fractions from Punica granatum Linn fruits (in Vietnamese), Journal of Traditional Vietnamese Medicine and Pharmacy 5(18) (2018) 59.

[7] S. Lenzen. The mechanisms of alloxan-and streptozotocin-induced diabetes. Diabetologia 51(2) (2008) 216.

[8] K. Shapiro, W.C. Gong . Natural products used for diabetes. Journal of the American Pharmaceutical Association 42(2) (2002) 217.

[9] O. Babova, A. Occhipinti, M.E. Maffei. Chemical partitioning and antioxidant capacity of green coffee (Coffea arabica and Coffea canephora) of different geographical origin. Phytochemistry 123 (2016) 33.

[10] A. Priftis, D. Stagos, K. Konstantinopoulos, C. Tsitsimpikou, D.A. Spandidos, A.M. Tsatsakis, et al. Comparison of antioxidant activity between green and roasted coffee beans using molecular methods. Molecular medicine reports 12(5) (2015) 7293.

[11] N. Liang, D.D. Kitts. Antioxidant property of coffee components: assessment of methods that define mechanisms of action. Molecules 19(11) (2014) 19180. 
[12] Vieira TMFdS. Potential antioxidant of brazilian coffee from the region of Cerrado. Food Science and Technology 38(3) (2018) 447.

[13] S.D. Kim. $\alpha$-Glucosidase inhibitor isolated from coffee. J Microbiol Biotechnol 25(2) (2015) 174.
[14] Y. Zheng, K. Liu, G. Jia, H. Li, L. Han, Y. Kimura Effect of hot-water extract of coffee seeds on postprandial blood glucose concentration in rats. (2007). 